\title{
Epidemiological study on Gastrointestinal Helminths of horses in Arsi-Bale highlands of Oromiya Region, Ethiopia
}

\author{
*1 Yacob Hailu Tolossa and ${ }^{1}$ Hagos Ashenafi \\ Addis Ababa University, College of Veterinary Medicine and Agriculture \\ P.O.Box. 34, Debre Zeit, Ethiopia \\ Yacob Hailu: e-mail: yamilaya2008@gmail.com
}

\section{Abstract}

A study to determine the prevalence and associated risk factors of gastrointestinal helminths in horses was conducted from October 2009 to May 2010 in three districts of the Arsi-Bale highlands of Oromiya region. A total of 2683 fecal samples for the coproscopic examination and 80 pooled samples for recovery of parasitic larvae were collected and processed in Asela Regional Veterinary Laboratory. The overall prevalence of gastrointestinal helminths was $84.4 \%$, out of which, $59.1 \%$ were mixed infections. Coprological examination revealed the existence of six species and five genera of helminths namely, Strongylus species $39.5 \%$, Cyathostomes $35.1 \%$, Trichostrongylus axei $29.0 \%$, Fasciola hepatica $23.1 \%$, Triodonthophorus species 13.9\%, Parascaris equorum $11.7 \%$, Oxyuris equi $1.8 \%$, Strongyloides westeri $0.7 \%$, Dictyocaulus arnifieldi $0.5 \%$, Anoplocephala species $0.3 \%$ and Gastrodiscus species $0.2 \%$. No significant variations $(\mathrm{P}>0.05)$ in prevalence of helminths were noticed in relation to districts, age and sex groups of horses, except in case of Parascaris equorum and Fasciola hepatica, in which prevalence was observed to significantly decrease and increase with age, respectively $(\mathrm{P}<0.05)$. The average egg per gram of faeces in this study was 745.2 with a range of 100 to 10,500 . The coproculture study revealed that Strongylus vulgaris, Strongylus edentatus and Cyathostomes were the major helminths larvae identified in the area during the study period. Thus, the present study revealed that gastrointestinal helminths are among the major health constrains of equines in the area demanding an urgent control intervention.

Keywords: Epidemiology, GI helminths, Horses, Ethiopia, Arsi-Bale, Oromyia.

http://dx.doi.org/10.4314/evj.v17i2.4 


\section{Introduction}

In developing countries like Ethiopia, the contribution of equines in the energy scenario is of the considerable significance as power source, for transportation, cultivation and post harvest activities in places where the road network is insufficiently developed (Feseha Gebreab, 1998). Only few regions in Northern western and south eastern of Ethiopia use equines for ploughing and threshing of crops is practiced (Feseha Gebreab et al.,, 1990; Hagos Ashenafi, 2005).

Ethiopia is home to the oldest feral horse population in Africa and the only wild horses left in east Africa, the Kundudo. One of the oldest recorded breeds, the Oromo bloodlines come from Ethiopia \& later spread along the coast of the Red Sea. They were first imported into England in 1861, where they quickly became prized for several of their unique characteristics. Arsi and Bale provinces of Oromia region are known with their densely populated equine population, mainly with Oromo breed horses (The Equinest, 2012).

As any other animal, equines are also vulnerable to a variety of diseases of biological origin, nutritional diseases or disorders and miscellaneous causes. Among which the most common entities leading to ill-health, suffering and early demise and finally death are infectious diseases and parasitism, which resulted in considerably reduced animals work output, reproductive performance and most of all their longevity (Feseha Gebreab, 1998).

Endo parasitic diseases dominated by gastro intestinal helminthes are the serious health problem contributing to poor body condition, reduced work out, poor reproductive performance and short life span. The deleterious effects of helminthes parasites on the equine hosts are well recognized globally and documented (Clayton, 1986). Large number of internal parasites has been identified in study done in some African countries including Ethiopia, Kenya, Zimbabwe, Burkina Faso and Morocco (Feseha Gebreab et al., 1990). In general, more than 150 types of internal parasites are known to infect horses (Johnson, 2000).

In Ethiopia various studies disclosed that strongyles, Parascaris equorum, bot stomach worms, lungworms, tapeworms and liver flukes to be the most prevalent gastrointestinal parasites of equines (Yoseph Shiferaw et al., 2001). Among gastrointestinal helminths, strongylosis is the most common diseases of horses throughout the world and cause death when control measures are neglected. (Urquhart et al., 1996). The disease process caused by strongyles can be produced by migrating larvae and by adult worms. Larval of Strongylus vulgaris are the most 
pathogenic, causing arthritis, thrombosis and thickening of artery wall (Soulsby, 1986). In Ethiopia Equines are mainly found in highlands and middle altitudes. These altitudes are known by presence of fasciolosis and other parasitic diseases in livestock (Feseha Gebreab, 1998).

Regarding Epidemiological study on helminthosis of equines in the Arsi-Bale highlands of Oromyia region, no detailed similar work has been performed, prior to this study. Therefore the objectives of the present study were to determine the prevalence of gastrointestinal helminths of equines and assess the effect of putative risk factors on the distribution of these parasites.

\section{Materials and Methods}

\section{Study area}

Arsi-Bale highlands are found in the Oromiya Regional State southeast of Ethiopia where Asela and Robe, the capitals of Arsi and Bale zones are located at 175 and 430 Kilo meters away from Addis Ababa respectively. Topographically, the altitude ranges from 1500 to 4250 meters above sea level, where a central plateau (2000-2500 meters above sea level predominates with a narrow lowland area. The area experiences a bimodal rainfall occurring from July to October and April to May. An average annual temperature of $20-25{ }^{\circ} \mathrm{C}$ and $10-15{ }^{\circ} \mathrm{C}$ and rainfall 400 to $700 \mathrm{~mm}$ in the lowlands whereas 1200 to $1400 \mathrm{~mm}$ in the highlands are recorded, respectively (CSA, 2003).

Equine population is the highest in Oromiya region mainly of the Arsi-Bale highlands (Arsi-Bale zone plan office, 2006). Bale Mountains National Park located in Bale highland of Oromiya region is the largest area of Afro-Alpine habitat in the whole of the continent which gives the visitor opportunities for unsurpassed mountain walking, horse trekking and the chances to view many of Ethiopia's endemic mammals (Ethiopia Tourism Commission, 2012).

Study animals and design

A cross sectional study involving a two stage cluster sampling technique was employed to conduct the study. Horses considered in this study were local (Oromo bloodlines) breeds in origin belonging to different age and sex groups. Young and adult groups were estimated using an age determination chart developed by Svendsen (1997). The age of sampled horses ranged from 1.2 to 27 years with an average of 8.7 years old. All horses were kept under typical traditional farmer's 
management conditions and allowed to graze without or poor supplementation (crop residues) and did not receive anthelminthic treatment before and during the study period. The body condition score was subjectively estimated based on guides published by Svendsen (1997).

\section{Sample Size}

A total of 2683 faecal samples of horses were collected to examine for the presence of helminth ova and 80 pooled samples for recovery of third stage larvae. The sample size was determined using standard procedures as described by Thrusfield (1995) for an infinite population, $50 \%$ estimated prevalence, $95 \%$ confidence interval and $5 \%$ allowable error for the estimate.

\section{Sampling Method}

A two stage cluster sampling technique was used to calculate the minimum sample size. Three districts namely Asela, Dodola and Goba were selected purposively based on equine population. Three peasant associations (PA) from each district were selected randomly using a lottery system. One village from each PA was selected randomly and all accessible horses in the village were sampled. Faecal samples were collected directly from the rectum using arm length rubber gloves and placed in $28 \mathrm{ml}$ glass, screw-corked universal bottles half filled with $10 \%$ formaldehyde (samples for coproculture were collected without preservative). A floatation technique was used to concentrate the helminth eggs and microscopic examination of feces for helminth ova using procedures as described by Hendrix (1998). A quantitative fecal examination, for egg per gram of feces (epg) determination was conducted using a modified McMaster egg counting technique according to Hanson (2000) to count helminth parasite eggs selectively on those samples positive for parasitic ova up on qualitative procedures. Additionally, 80pooled fecal samples were collected and used to differentiate parasitic larvae whose eggs could not be distinguished by examination of fresh feces using a procedure described by Hendrix (1998).

\section{Data analysis}

Collected data was subjected to SPSS 11.5 software of the computer program for the statistical analysis. Based on the type of data, the association between risk factors and distribution of parasites were analyzed using bivariate and multivariate statistical analysis of logistic regressions, the chi square test and analysis of 
variance. The strengths of associations were determined using estimates of odds ratio. Statistical significance was set at $\mathrm{P}<0.05$ according to Thrusfield (2005).

\section{Results}

\section{Coprological findings}

The coprological examination in the present study revealed the existence of 11 different gastrointestinal helminths of horses (6 at species and 5 genus levels), with different prevalences. These include : Strongylus species $39.5 \%$, Cyathostomes $35.1 \%$, Trichostrongylus axei $29.0 \%$, Fasciola hepatica $23.1 \%$, Triodonthophorus species 13.9\%, Parascaris equorum $11.7 \%$, Oxyuris equi $1.8 \%$, Strongyloides westeri $0.7 \%$, Dictyocaulus arnifieldi $0.5 \%$, Anoplocephala species $0.3 \%$ and Gastrodiscus species $0.2 \%$. The overall prevalence of gastrointestinal helminths of horses was $84.4 \%$, out of which $59.1 \%$ were mixed infections with two or more types of helminths (Table 1 and 2).

Table 1. Prevalence of GI helminths in horses in relation to different risk factors in three study districts

\begin{tabular}{lccccc}
\hline Risk factors & No. samples & \multicolumn{2}{c}{ Overall helminth ova } & \multicolumn{2}{c}{ Mixed infection } \\
& examined & No. positive & Prevalence (\%) & No. positive & $\begin{array}{c}\text { Prevalence } \\
\text { (\%) }\end{array}$ \\
\hline $\begin{array}{l}\text { District: } \\
\text { Asela }\end{array}$ & 915 & 742 & 81.1 & 442 & 48.3 \\
Dodola & 952 & 802 & 84.2 & 467 & 49.1 \\
Goba & 816 & 721 & 88.4 & 430 & 52.7 \\
\hline Age: & & & & & \\
$<4$ years & 391 & 337 & 86.2 & 214 & 54.7 \\
4-8 years & 1346 & 1121 & 83.3 & 655 & 48.7 \\
$>8$ years & 946 & 807 & 85.3 & 470 & 49.7 \\
\hline Sex: & 1728 & 1444 & 83.6 & 847 & 49.0 \\
Male & 955 & 821 & 86.0 & 497 & 52.0 \\
Female & & & & & \\
\hline Body condition: & 1310 & 1101 & 84.0 & 655 & 50.0 \\
& 1308 & 1113 & 85.1 & 655 & 50.1 \\
Poor & 65 & 51 & 78.5 & 29 & 44.6 \\
Medium & 2683 & 2265 & 84.4 & 1339 & 59.1 \\
Good & & &
\end{tabular}


There was no significant difference $(\mathrm{P}>0.05)$ in the prevalence of gastrointestinal helminths in districts, age groups, sexes and body condition of horses (Table 1).

There was statistically significant variations in the prevalence of Strongylus species among sex $(\mathrm{P}<0.05)$ of the examined horses. Accordingly, female animals were more affected with Strongylus species (43.2\%) than males (37.4 \%). However, districts, age and body condition did not seem to have significant effect on Strongylus species infection $(\mathrm{P}>0.05)$ (Table 2). On the other hand, the prevalence of Cyathostomes in different districts was significantly $(\mathrm{P}<0.05)$ variable (Table 2$)$. There was significant variation in the prevalence of Trichostrongylus axei among the three districts $(\mathrm{P}<0.05)$ but age, sex and body condition were not seen to have significant effects $(\mathrm{P}>0.05)$.

Table 2. Prevalence of GI helminths of horses in relation to different risk factors in three study districts

\begin{tabular}{lcccccc}
\hline $\begin{array}{l}\text { Risk } \\
\text { factors }\end{array}$ & $\begin{array}{l}\text { Strongylus } \\
\text { species }\end{array}$ & Cyathostomes & T. axei & $\begin{array}{l}\text { Fasciola } \\
\text { hepatica }\end{array}$ & $\begin{array}{l}\text { Parascaris } \\
\text { equorum }\end{array}$ & Triodonthophorus \\
\hline $\begin{array}{l}\text { District: } \\
\text { Asela }\end{array}$ & $42.3 \%$ & $32.8 \%$ & $30.6 \%$ & $12.6 \%$ & $11.7 \%$ & $15.2 \%$ \\
$\begin{array}{l}\text { Dodola } \\
\text { Goba }\end{array}$ & $33.5 \%$ & $33.6 \%$ & $24.8 \%$ & $37.9 \%$ & $10.2 \%$ & $13.2 \%$ \\
\hline Age: & $43.3 \%$ & $39.6 \%$ & $32.2 \%$ & $17.5 \%$ & $13.6 \%$ & $13.1 \%$ \\
$<4$ & 50.1 & $35.0 \%$ & $27.1 \%$ & $16.4 \%$ & $21.0 \%$ & $15.1 \%$ \\
$4-8$ & 37.2 & $34.2 \%$ & $27.3 \%$ & $23.9 \%$ & $10.9 \%$ & $13.3 \%$ \\
$>8$ & 37.9 & $36.3 \%$ & $32.3 \%$ & $24.5 \%$ & $9.1 \%$ & $14.2 \%$ \\
\hline Sex: & & & & & & \\
Male & 37.4 & $35.8 \%$ & $28.3 \%$ & $23.8 \%$ & $9.5 \%$ & $14.2 \%$ \\
Female & 43.2 & $33.8 \%$ & $30.4 \%$ & $21.8 \%$ & $15.7 \%$ & $13.2 \%$ \\
\hline Body & & & & & & \\
condition: & & & & & & \\
Poor & 40.0 & $33.9 \%$ & $26.3 \%$ & $25.1 \%$ & $13.2 \%$ & $15.0 \%$ \\
Medium & 39.1 & $36.8 \%$ & $32.0 \%$ & $21.2 \%$ & $10.2 \%$ & $13.1 \%$ \\
Good & 35.4 & $24.6 \%$ & $23.1 \%$ & $20.0 \%$ & $12.3 \%$ & $6.2 \%$ \\
\hline Total & 39.5 & $35.1 \%$ & $29.0 \%$ & $23.1 \%$ & $11.7 \%$ & $13.9 \%$ \\
\hline
\end{tabular}

The variation in the prevalence of $F$. hepatica among the three districts was highly significant $(\mathrm{P}<0.05)$ and horses in Dodola were 4.29 and 2.9 times more likely to be infected by $F$. hepatica than horses in Asela and Goba districts, respectively. The prevalence of $F$. hepatica was seen to increase as age advances. The age variation in the prevalence of $F$. hepatica was statistically significant $(\mathrm{P}<0.05)$ 
where horses more than 8 years old were 1.65 times more likely to be infected with $F$. hepatica than horses less than 4 years of age. Likewise, horses between 4-8 years of age were 1.6 times more likely to be infected with $F$. hepatica than horses less than 4 years of age. There was a statistically significant difference in the prevalence of $F$. hepatica with body condition of horses $(\mathrm{P}<0.05)$. However, the effect of sex on the prevalence of Fasciola hepatica was not statistically significant $(\mathrm{P}>0.05)($ Table 2).

The effect of age and sex variations in the prevalence of $P$. equorum were statistically significant $(\mathrm{P}<0.001$ and $\mathrm{P}<0.05)$ respectively. Horses less than 4 years of age were 2.65 and 2.16 times more likely to be infected with $P$. equorum than those of 4-8 years and more than 8 years of age, respectively. Female horses were found being more susceptible to $P$. equorum infection than their counter males (Table 2). The variation in the prevalence of Triodonthophorus species due to district, age, sex and body condition were not statistically significant $(\mathrm{P}>0.05)$ (Table 2).

\section{Faecal egg counts}

The average egg per gram (epg) of feces in this study was 745.2 with a range of 100 to 10,500 . These variations due to difference in district, age, sex and body conditions were not statistically significant $(\mathrm{P}>0.05)$ (Table 3$)$.

Table 3. Helminth egg per gram of feces (epg) counts in horses in relation to different risk factors in the three study districts

\begin{tabular}{llll}
\hline Risk factors & No. of samples & Mean epg output & Standard deviation \\
\hline District: & & & \\
Asela & 915 & 591.98 & 147.26 \\
Dodola & 952 & 636.91 & 385.88 \\
Goba & 816 & 1020.52 & 195.84 \\
\hline Age: & & & \\
$\quad<4$ years & 391 & 750.03 & 295.63 \\
4-8 years & 1346 & 753.77 & 387.51 \\
> 8 years & 946 & 731.03 & 230.64 \\
\hline Sex: & & & \\
Male & 1728 & 747.08 & 365.88 \\
Female & 955 & 741.84 & 241.00 \\
\hline Body condition: & & & \\
Poor & 1310 & 734.51 & 361.90 \\
Medium & 1308 & 756.82 & 291.10 \\
Good & 65 & 722.97 & 253.62 \\
\hline Total & 2683 & 745.21 & 326.90 \\
\hline
\end{tabular}




\section{Differential larval counts}

The coproculture performed on 80-pooled fecal samples revealed three Strongyle genera, which were: Strongylus vulgaris $38.46 \%$, Strongylus edentatus $30.77 \%$, Cyathostomes species $23.08 \%$ and Triodonthophorus species $7.70 \%$ (Table 4).

Table 4. Result of differential larval counts recovered by coproculture from 80pooled fecal samples from horses in the study areas.

\begin{tabular}{lll}
\hline Species/Genus of larvae & No. of larvae & Proportion \\
\hline Strongylus vulgaris & 3077 & $38.46 \%$ \\
Strongylus edentatus & 2461 & $30.77 \%$ \\
Cyathostomes species & 1846 & $23.08 \%$ \\
Triodonthophorus species & 616 & $7.70 \%$ \\
\hline Total & 8000 & 100.00 \\
\hline
\end{tabular}

\section{Discussion}

The results of the present study clearly demonstrated that helminth infections are highly prevalent in horses of Arsi-Bale highlands of Oromiya Region. This is in line with previous report from Ethiopia by Feseha Gebreab (1998) and other countries such as USA (Reinmeyer et al., 1984) and South Africa, (Krecek et al., 1989) which indicated prevalence ranging between $80 \%$ and $100 \%$.

The current study also demonstrated 11 different types of helminth parasites (6 at species and 5 at genus levels), of which Strongylus species and Cyathostomes were found to be the dominant ones. This is in agreement with the findings in other parts of Ethiopia by Fiseha Gebreab et al., (1990) who recorded Cyathostomes in 85-92 $\%$, Strongylus species in $74-80 \%$, Triodonthophorus species in $74-78 \%, P$. equorum $38.4-44.7 \%$ as the major helminth parasites in equines in central Ethiopia.

The present study indicated that polyparasitism to be the major problem in the area. The presence of more than one helminths in horses in these study areas may be related with lack of control measures against helminth parasites. Specifically the lack of regular deworming tends that might have attributed to the incidence of polyparasitism. The climatic condition of Arsi-Bale highlands of Oromiya region where rainfall is frequent and temperature is mild also favors the development and survival of infective larvae for most part of the years. Owing to the huge equine population in the study area considerable contamination to the communal pasture grazing system could be the other factor which favors polyparasitism. Arsi- Bale 
highlands of Oromiya region have temperate type of climate being cool for most parts of year with a heavy annual rainfall. Furthermore the equine biomass in ArsiBale highlands of Oromiya region is the highest for the country where animals of deferent age and sex group usually graze on communal pasture facilitated easy transmission of these parasitism.

The prevalence of Strongylus (39.5 \%) and Cyathostomes species (35.1\%) observed in this study were lower compared to those reported by Fiseha Gebreab (1998) where it was found that S. vulgaris $80 \%$ and Cyathostomes $76.1 \%$ in horses of Debre Zeit town. Similarly, Krecek et al., (1989) reported a prevalence of $94 \%$ for S. vulgaris in horses of South Africa. In the present study, the reported prevalence was lower due to the fact that sampling was conducted partly in the dry season of the year.

The moderate prevalence of Trichostrongylus axei (29.0\%) observed in this study was in agreement with reports by Krecek et al., (1989) and Feseha Gebreab et al., (1990) 1998; which ranged from 6-40\%. The prevalence of Triodonthophorus species in this study (13.9\%) was also lower than previous findings of Krecek et al., (1989) and Feseha Gebreab (1998) who reported $23 \%$ and $35 \%$, respectively. However, it was much higher than the finding of Reinmeyer et al., (1984) which was $3.6 \%$. The possible explanation for the observed variation in prevalence could be attributed to differences in agro-ecology, sampling season as well as equine management system.

The overall prevalence of $F$. hepatica was $23.1 \%$ which seems higher than the previous findings of Feseha Gebreab (1998) who reported a prevalence of $9.0 \%$ in Menagesha and central Ethiopia and comparable with the results of Gezahegn Eshete (2000) who reported $27.1 \%$ prevalence in cart mules in Bahir Dar Northwestern Ethiopia. This is attributed to the presence of wide marshy and swampy vast communal grazing areas which is common in many parts of Ethiopia. Moreover, there was an increasing trend in the prevalence of fasciolosis with age of equines, which can be explained from the fact that older animals might have a high risk for exposure to Fasciola than the young.

The prevalence of $P$. equorum in the present study $(11.7 \%)$ was relatively lower than that of Gezahegn Eshete (2000) who reported $43.8 \%$ in Bahir Dar Northwestern Ethiopia. The prevalence of $P$. equorum was significantly higher in young horses $(21.0 \%)$ than older horses $(9.1 \%)$. This was not unexpected because $P$. equorum is more of a problem of young horses as immunity develops following 
exposure during older age (Hundson, 1990; Urquhart et al., 1996). Acquired resistance to $P$. equorum usually develops before the second year of life and therefore, cases are highly reported from younger animals (Urquhart et al., 1996). Young animals were seem to more susceptible than adults. Feseha Gebreab (1998) reported Strongyliodes westeri and $P$. equorum frequently blamed to affect young species of equines. The prevalence of $P$. equorum was also higher in mares (15.7 $\%)$ than their counterpart stallions $(9.5 \%)$. This can be justified by the fact that mares have a close relation to their foals, which favors frequent recycling of the parasite between the dam and foal. Heavy infections of $P$. equorum cause impaction and perforation leading to fatal peritonitis (Urquhart et al., 1996).

The prevalence of Oxyuris equi $1.8 \%$, Strongyloides westeri $0.7 \%$, Dictyocaulus arnifieldi $0.5 \%$, Anoplocephala species $0.3 \%$ and Gastrodiscus species $0.2 \%$ is quite lower than previous reports by Yoseph Shiferaw et al., (2001). Anoplocephala magna and other related but less common and smaller tapeworm such as Paranoplocephala perfoliata are the only adult cestodes found in horses (Soulsby, 1986). This low prevalence of cestodes in horses in this study could be due to the seasonality of orbited mites (vectors) as described by Soulsby (1986).

A relatively higher mean egg per gram of feces 745.2 epg output was observed in horses of the three districts. This result was in agreement with findings of Krecek et al., (1986) and Newmarket (1986) who reported the spring rise of Strongyle egg output in grazing horses. This is also attributed to the favorable condition of wet and humid environment to the biology of these parasites.

The differential larval count indicated that $S$. vulgaris, S. edentatus and Cyathostome species were the major parasites of horses in the studied districts. This result is line with the findings of Feseha Gebreab (1998).

The results of the present study disclosed that polyparasitism is one of the commonest ill-causing factors and indeed the main cause of early demise of horses in the study districts. However, the problem due to gastrointestinal helminths of equines in the study area was given less attention because of its sub clinical nature. Hence strategic treatment of equines should be undertaken on the basis of sound and complete understanding on the epidemiology of gastrointestinal helminths of equines in the study districts. 


\section{References}

Arsi-Bale zone plan office., 2009. Zonal Agricultural Compiled Report, Oromiya region, Ethiopia, pp7-11.

Ethiopia Tourism Commission., 2012. Bale Mountain National Park. Online: www.Selamta.net/bale mountain national_park.htm.

Clayton, H. M., 1986. Ascarids: recent advances in the veterinary clinics of North America. Equine Pract 2: 263-280.

CSA, 2003., Central Statistics Authority: The 2001/02 Ethiopian Agricultural Sample Enumeration (ESAE), Executive summary, Addis Ababa, Ethiopia.

Eshete, G., 2000. A preliminary study on health and productivity status of "Ghari" mules in and around Bahir Dar. DVM thesis. Addis Ababa University, Faculty of Veterinary Medicine, Debre Zeit.

Gebreab, F., Abdela, M., Jobre, Y., 1990. Vermicular Endoparasitism in donkeys of Debre Zeit and Menagesha, Ethiopia, Strategic treatment with Ivermectin and Fenbendazole, Paper presented at the International Colloquium on Donkeys. Mules and Horses in tropical Agricultural Development, Held in Edinburgh, Scotland $3^{\text {rd }}$ to $6^{\text {th }}$ September, 1990, 151-155.

Gebreab, F., 1998. Helminth Parasites of Working Equids: The African perspective. Proceedings of the $8^{\text {th }}$ International Conference on Infectious Diseases of equines. Dubai, UAE. 318-324.

Ashenafi, H., 2005. Serological and parasitological survey of Dourine (Trypanosoma equiperdum) in selected sites of Ethiopia. MSc thesis. Addis Ababa University, Faculty of Veterinary Medicine, Debre Zeit.

Hassen, K., 2000. A preliminary study on the socio economic importance, health problems and other management constraints of horse in mid and high land areas of north Gondar. DVM thesis. Addis Ababa University, Faculty of Veterinary Medicine, Debre Zeit Ethiopia.

Hendrix, C., 1998. Diagnostic Veterinary Parasitology. $2^{\text {nd }}$ edition, Mosby, London.

Hundson, D., Grotelueschen, D., Rice, D., 1990. Equine Internal Parasites. University of Nebraska. Cooperative Extension Educational Programs.

Krecek, R., Reineceke, R., Horak, I., 1989. Internal Parasites of Horses on mixed Grassveld and Bushveld in Transvaal, Republic of South Africa. Vet. Parasitol., 34: 135-143. 
Reinmeyer, C., Smith, S., Gabel, A., Herd, R., 1984. The prevalence and intensity of internal parasites of horses in the USA. Vet. Parasitology., 15: 75-83, 1984.

Shiferaw,Y., Gebreab, F, Abebe, W., 2001. Survey on Helminthosis of Equine in Wonchi. Ethiop. Vet. J, 5 (1): 47-61.

Soulsby, E., J., 1986. Helminthes, Arthropods and Protozoa of domesticated animals. $7^{\text {th }}$ edition Lea and Febiger Philadelphia, USA. pp. 357-504.

Svendsen, E.D., 1997. Donkeys abroad. The professional hand book of the donkey ( $3^{\text {rd }}$ ed.). White books limited. London, UK.

The Equinest., 2012. Horse breeds from Ethiopia. Online: www.info[at]theequinest.com.

Thrusfield, M., 1995. Veterinary Epidemiology. $2^{\text {nd }}$ edition, UK; Black well Science Ltd. Pp 182-189.

Thrusfield, M., 2005. Veterinary Epidemiology, Third Edition, Blackwell Science Ltd., UK, pp. 229-245.

Urquhart, G. M., Armour, J., Duncan, J. L., Dunn, A. M., Jennings, F. W., 1996. Veterinary Parasitology. $2^{\text {nd }}$ ed. Black well science limited, London. 307. 